\title{
Notes on the vocalizations of Australasian Figbird (Sphecotheres vieilloti)
}

Peter Boesman

In the following we briefly analyze and compare voice of the different races of Australasian Figbird (Sphecotheres vieilloti). We also try to quantify the extent of any vocal differences using the criteria proposed by Tobias et al. (2010), as a support for taxonomic review.

We have made use of sound recordings available on-line from Xeno Canto (XC) and Macaulay Library (ML).

Most available recordings are of the race flaviventris, with just a few from vielloti and even less from other races.

I have therefore checked if the typical notes in the song of vielloti also occur in flaviventris:

* low-pitched note followed by descending whistle, with some burry quality in part of the notes

vielloti

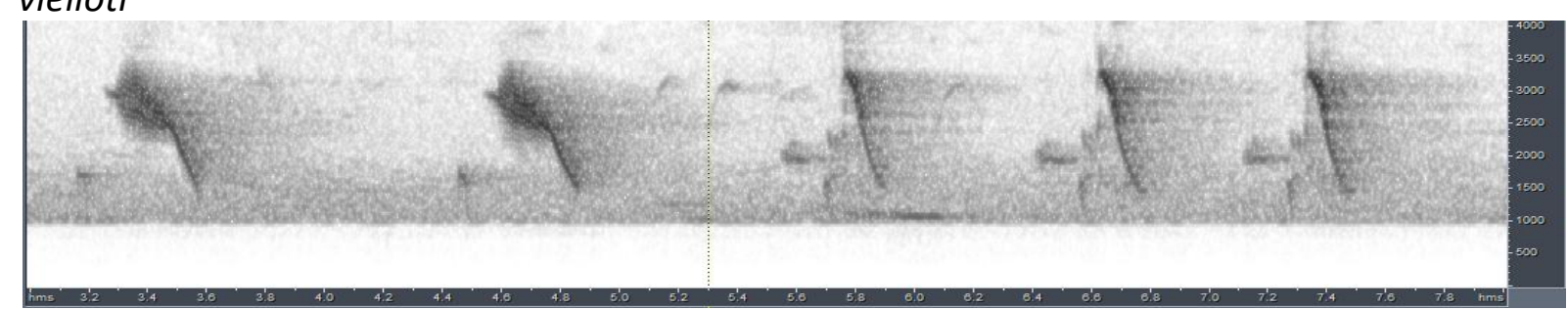

flaviventris

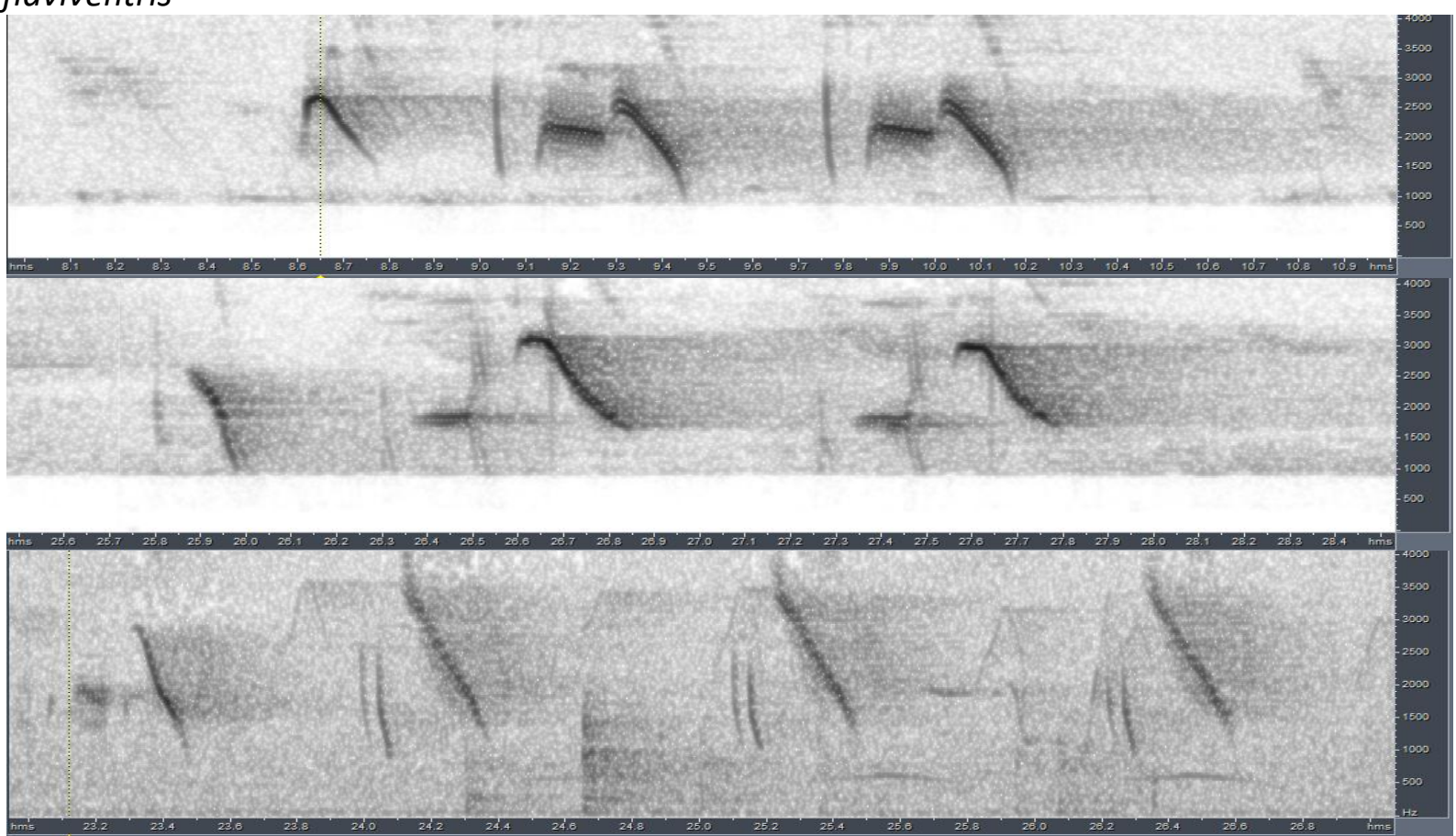




\section{HANDBOOK OF THE wirof Alve \\ ORNITHOLOGICAL NOTES}

* soft low-pitched notes followed by pure descending whistle, without any burry quality vielloti

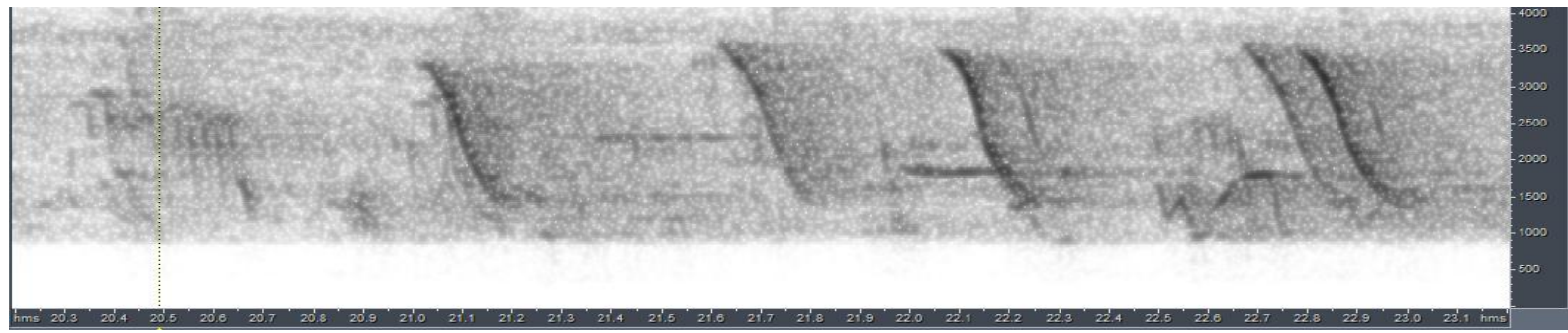

\section{flaviventris}

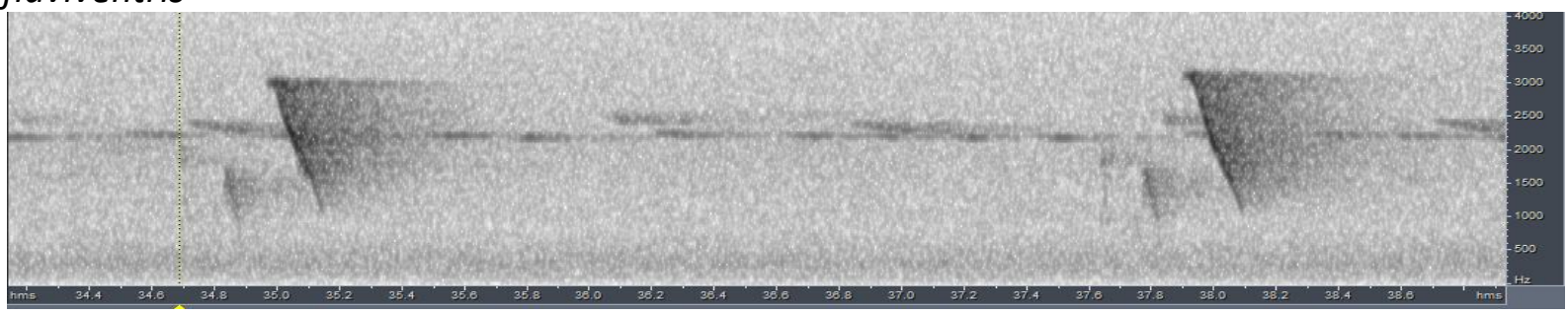

* Nasal notes and whistle vielloti

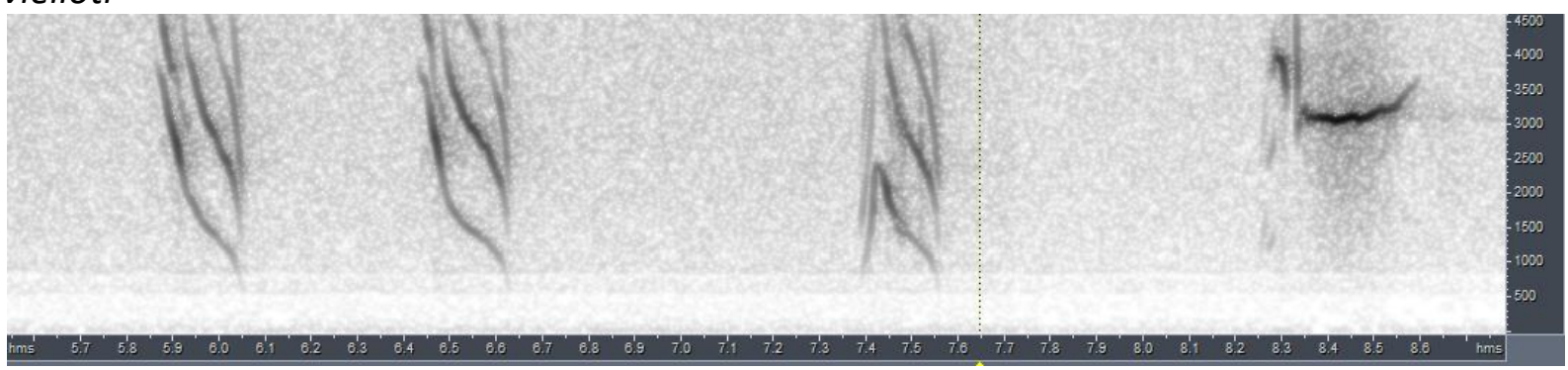

flaviventris

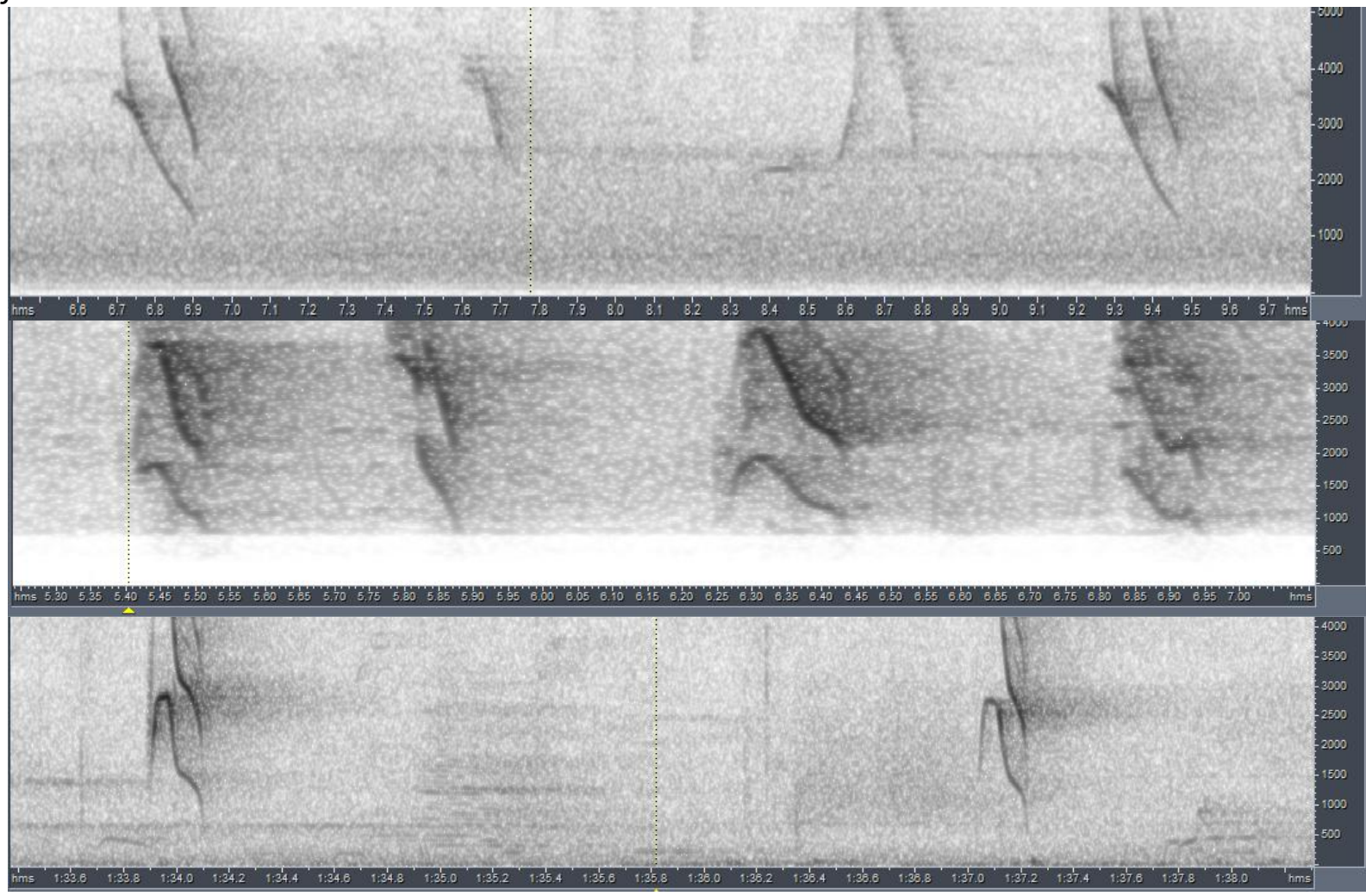



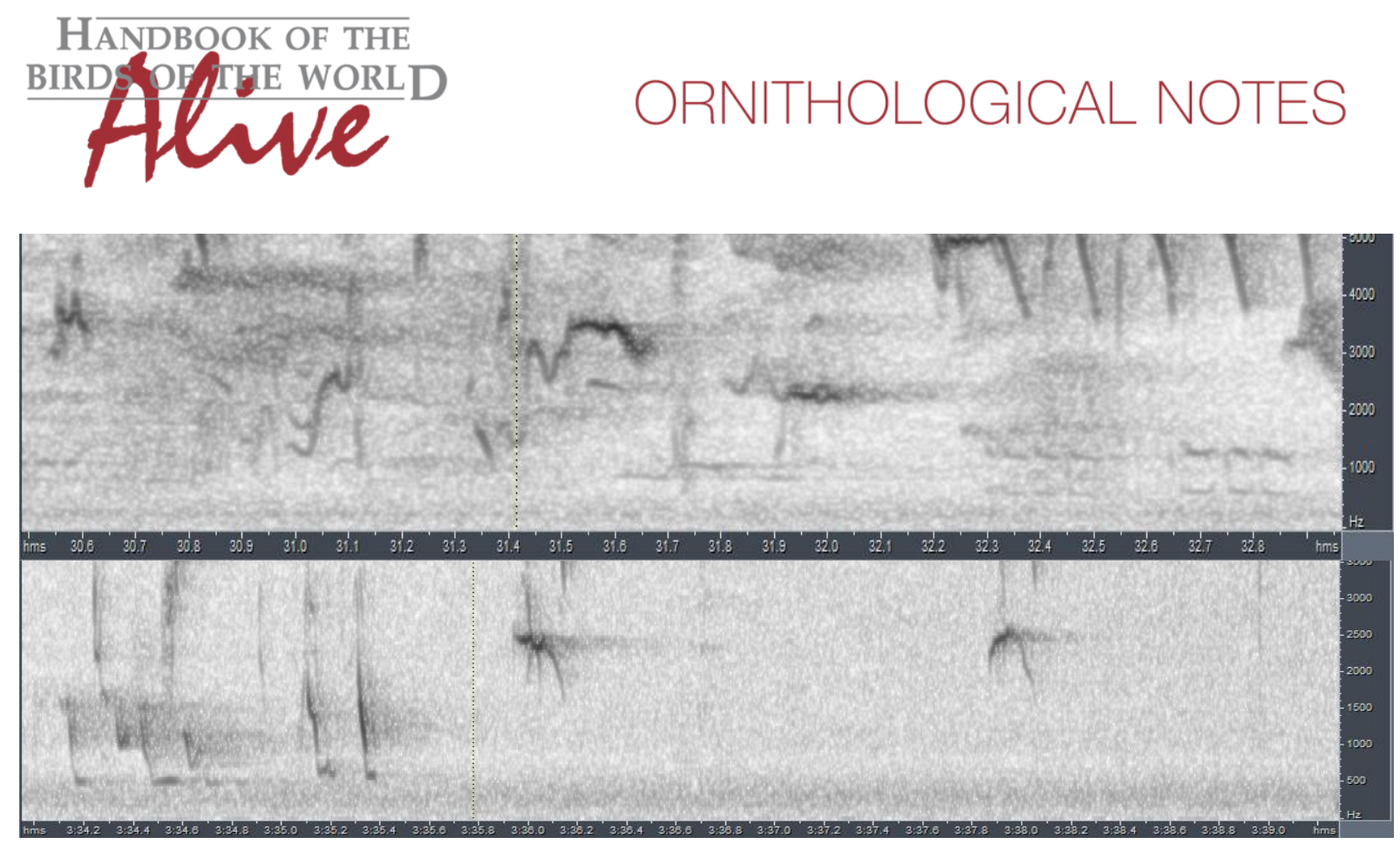

From the above, it is clear that the vocabulary of vielloti seems to fall within the range of flaviventris.

It would require a large data set to determine whether there is any consistent difference among these 2 races. In any case, even then vocal score by application of Tobias criteria would be (very) low.

This note was finalized on 9th October 2015, using sound recordings available on-line at that moment. We would like to thank in particular the sound recordists: Patrik Åberg, Marc Anderson, Benjamin Clock, Krzysztof Deoniziak, Fernand Deroussen, Phil Gregory, Emma Greig, Cedar Mathers-Winn, Linda Macaulay, David McCartt, Nick Talbot, Bas Van Balen and Fred Van Gessel.

\section{References}

Tobias, J.A., Seddon, N., Spottiswoode, C.N., Pilgrim, J.D., Fishpool, L.D.C. \& Collar, N.J. (2010). Quantitative criteria for species delimitation. Ibis 152(4): 724-746.

\section{Recommended citation}

Boesman, P. (2016). Notes on the vocalizations of Australasian Figbird (Sphecotheres vieilloti). HBW Alive Ornithological Note 159. In: Handbook of the Birds of the World Alive. Lynx Edicions, Barcelona. (retrieved from http://www.hbw.com/node/932089 on 18 August 2016). 